\title{
Development and energy evaluation of phase change material composite for
}

\section{building energy-saving}

Ru Ji ${ }^{1}$, Zehui Zou ${ }^{1}$, Lei $\mathrm{Liu}^{2}$, Shen $\mathrm{Wei}^{3}$, Shilin $\mathrm{Qu}^{1 *}$

${ }^{1}$ School of Civil and Resource Engineering, University of Science and Technology Beijing, 100083, Beijing, P.R. China

${ }^{2}$ School of Metallurgical and Ecological Engineering, University of Science and Technology Beijing, Beijing 100083, P. R. China

${ }^{3}$ Bartlett School of Construction and Project Management, University College London (UCL), WC1E 7HB, London, UK

*Corresponding author: q.shilin@163.com

\begin{abstract}
Phase change materials (PCMs) contributed to building energy-saving and thermal comfort, through increasing the thermal capacity of building envelopes. In this study, a phase change material composite was developed by using the PCMs mixture of capric acid (CA) and lauric acid (LA) as the primary phase change energy storage agent and using the solid waste fly ash as a carrier material. The results showed that for Guangdong the ideal PCMs mixture should have a transition temperature of $25.5^{\circ} \mathrm{C}$, which could be got by using mass ratio of CA/LA of 4:6. Then experiment results also indicate that the optimum adsorption ratio of $2: 1$ (FA/PCMs) was detected for the synthesis of this FA/PCMs composite, which has the latent heat of $45.38 \mathrm{~J} / \mathrm{g}$ and exists excellent thermal reliability. Moreover, simulation results by using EnergyPlus show that the proposed composite has a good building energy-saving effect.
\end{abstract}


Keywords: Phase change materials; fly ash; capric acid; lauric acid; building energysaving.

\section{Introduction}

In a whole building life, whether under construction or during operation, it consumes huge energy and resource, and causes some environmental problems, such as $\mathrm{CO}_{2}$ emissions [1-3]. Currently, buildings have contributed to a significant part in total society energy consumption, and it is still growing at a rapid rate [4]. According to the literature, buildings section has accounted for more than $40 \%$ of total primary energy in the world, in which more than $70 \%$ occurs during its operation, such as cooling and heating [5-6]. Therefore, energy-saving in buildings is a tough task for the sustainable development of society.

As a main factor to affect the building energy load, the building envelope with excellent thermal properties is an efficient method for realizing the building energysaving [7]. For now, thermal insulation layer attached to building envelopes is a main mode for the energy-saving in buildings [8], and the commonly used insulation materials mainly include rock wool, slag wool, glass wool, polystyrene foam, expanded perlite, foamed concrete and so on [9-10]. Although the thermal insulation layer could reduce the heat transfer coefficient of the envelope structure, it only serves as a heat insulation function and plays a limited role in energy storage [11].

For building envelopes, the strict energy-saving standards are based on the two thermal properties values of the envelope materials, i.e. thermal conductivity and 
thermal capacity [12-15]. Phase change materials (PCMs) can effectively improve the thermal inertia of materials due to their huge latent heat, so PCMs have received much attention in the recent energy-saving applications and research of building envelopes. For example, Boussaba [16] synthesized a PCMs composite with low-cost and ecofriendly for the application in building envelopes. Zhou et al. [17] through investigating heat-transfer mechanism of envelopes with PCMs, indicated the effect factors on PCMs function. Sarı and Mankel [18-19] proposed a formed PCMs/cement composite with stable characteristic for building envelopes use.

However, there are many limitations in the application of the construction materials incorporating PCMs, such as leakage and corrosion, which problems could be solved by the synthesis technology of shape-stabilized PCMs [20-22]. Moreover, there is another problem is that the transition temperature of the present PCMs is usually not suitable for the use in building envelopes. Capric acid and lauric acid not only have high latent heat of phase transformation, but also can obtain PCMs composite with appropriate phase transition temperature in indoor comfort zone when mixed in different proportions [23]. Then the synthesized PCMs mixture could be adsorbed by a carried material to prepare the shaped PCMs for envelopes use. Fly ash (FA), a byproduct of coal combustion in thermal power plants [24-25], is an excellent carrier material, due to its good porous structure [26]. According to the literature, the annual generation of fly ash has reached up to 580 million tones in China by 2015, while only less than $70 \%$ of fly ash were efficiently utilized [27], leading to land occupies and 
many environmental problems [28-29]. Therefore, using fly ash as a carrier material for energy-saving application of building envelopes is a win-win method.

This study, therefore, was motivated to develop and assess a new PCMs composite. Firstly, a reference method, to design the best transition temperature of PCMs according to a simulation in a real building, was proposed. Secondly, a new phase change material composite was synthesized by mixing capric acid and lauric acid as PCMs mixture and being absorbed by fly ash. Then, the properties of synthetic composites would be studied and discussed systematically. Thirdly, the energy-saving performance of the proposed PCMs composite would be evaluated by using EnergyPlus Software.

\section{Methodology}

\subsection{Characteristics of raw materials}

In this study, two kinds of raw materials were used, including PCMs and carrier materials. For preparing PCMs, capric acid (CA) and lauric acid (LA) were used, due to their appropriate transition temperatures when mixing. While, as an excellent carrier material, fly ash (FA), collected from a power plant in Shanxi province, was chosen, due to its good porous structure.

First, the thermal properties of the capric acid and the lauric acid were tested by using DSC measurements, as shown in Figure 1. It can be seen that the transition temperatures are $32^{\circ} \mathrm{C}$ and $45^{\circ} \mathrm{C}$, with the latent heat of $169.14 \mathrm{~kJ} / \mathrm{kg}$ and $187.65 \mathrm{~kJ} / \mathrm{kg}$, for capric acid and lauric acid, respectively. 


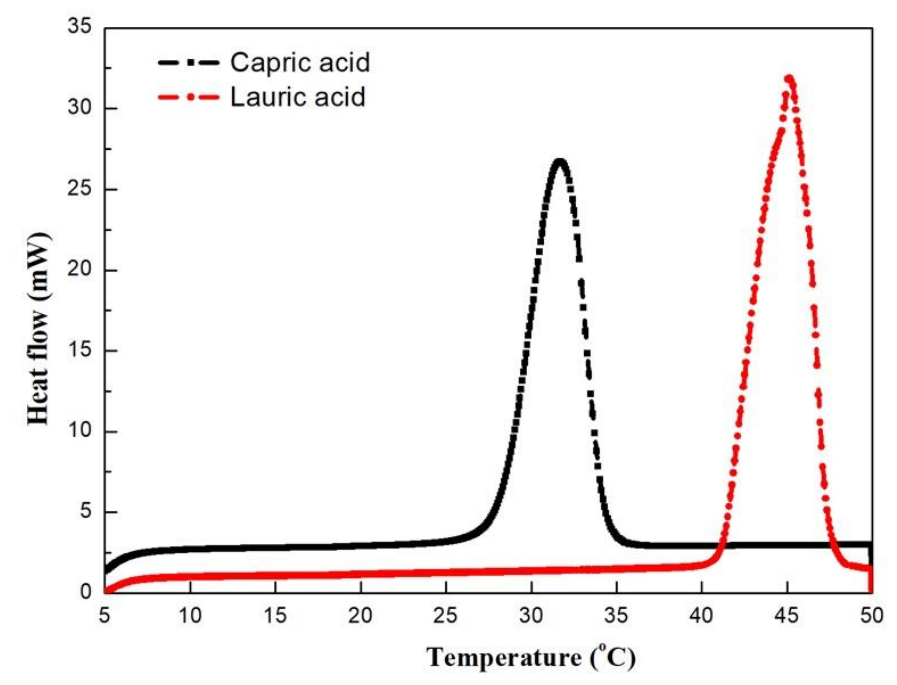

Figure 1: DSC curves of the capric acid and lauric acid

Secondly, the carrier material fly ash was tested by XRF, SEM, and XRD. As shown in Table 1, fly ash mainly consists of $\mathrm{SiO}_{2}$ and $\mathrm{Al}_{2} \mathrm{O}_{3}$, accounting for high up to 84.98wt\%, and some other oxide such as $\mathrm{Fe}_{2} \mathrm{O}_{3}$ and $\mathrm{CaO}$. Next, Figure 2a indicates that fly ash particles are spherical. Besides, from the XRD pattern in Figure 3a, it can also be found that for the original fly ash, the main crystal phase is mullite with a small amount of quartz, silicon disulfide $\mathrm{SiS}_{2}$ and calcium carbonate $\mathrm{CaCO}_{3}$.

Moreover, to improve the adsorption capacity of fly ash, it was modified by heat treating for 2 hours in a furnace at $800^{\circ} \mathrm{C}$ and allow to furnace cool. Then the heattreated modified fly ash was tested by SEM and XRD, to figure out what is happened in it. The SEM images in Figure 2 indicate that after modifying the opening pore phenomenon of the modified fly ash particles is more obvious, compared with that of the previous unmodified fly ash. While After heat-treated modification, the diffraction patterns in Figure 4 show that a new crystal phase, calcium sulfate $\mathrm{CaSO}_{4}$, is formed, due to the chemical reaction of $\mathrm{CaCO}_{3}$ and $\mathrm{SiS}_{2}$ [30]. In specifically, the heat-treatment 
could destroy the crystal phase structure in fly ash. Then the carbon, that is not fully combusted in the raw powder of fly ash, would react with oxygen to form carbon dioxide gas. The gas would destroy the surface structure of the fly ash during the escape process. Finally, the pores in the body of fly ash would be enlarged, increasing the internal porosity of the fly ash.
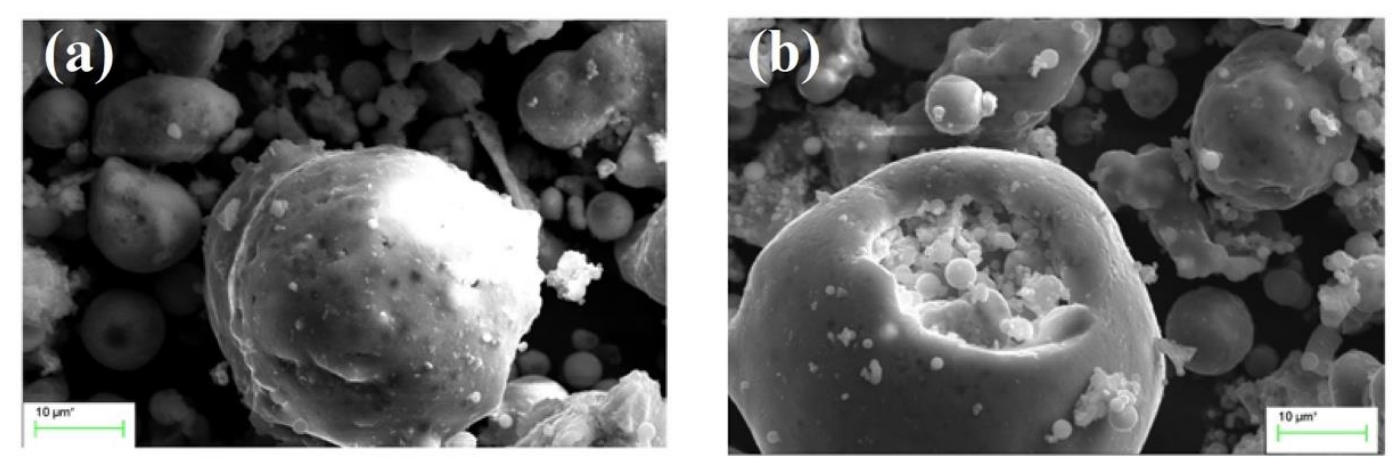

Figure 2: SEM images of the fly ash (a) before and (b) after modification

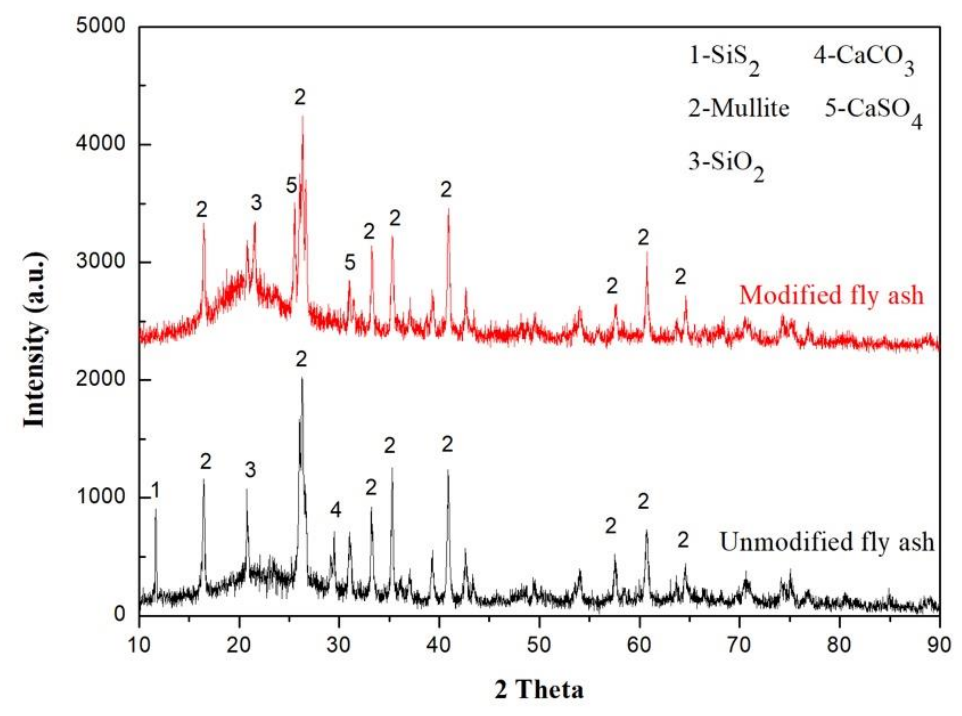

Figure 3: XRD patterns of the fly ash before after and after modification

\subsection{PCMs preparation}

\subsubsection{CA-LA preparation}

As shown in Figure 1, both melting points of capric acid and lauric acid are high, which is not suitable for energy-saving in building envelopes. However, after mixing 
the two materials, it becomes a eutectic system, and the melting point of the mixture is lower than the melting point of any single original material. Therefore, in this study, in order to prepare PCMs with the appropriate transition temperature, Schroder's equation (1) could be applied to calculate the mixing rate of the capric acid to the lauric acid [31]. Where $x_{A}$ is the molar fraction of compound $\mathrm{A} ; \Delta H_{A}$ equals to the fusion latent heat of compound $\mathrm{A}, \mathrm{J} / \mathrm{mol} ; T$ and $T_{f}$ are the transition temperatures of the mixture and compound A, respectively, $\mathrm{K} ; R$ is the gas factor, which is equal to $8.315 \mathrm{~J} / \mathrm{K} / \mathrm{mol}$.

$$
T=\frac{1}{\frac{1}{T_{f}}-\frac{R \ln x_{A}}{\Delta H_{A}}}
$$

The CA-LA PCMs mix rate (CA:LA) of the capric acid to the lauric acid and the corresponding theoretical phase transition temperatures could be got, as shown in Table 2. Table 2 indicates that with an increase of the capric acid content, the theoretical phase transition temperature would decrease firstly, then increase.

Then the capric acid and lauric acid were weighed separately and put them together in a beaker, then the beaker was placed in a water bath at $50^{\circ} \mathrm{C}$, finally, the mixture was keeping mixed in 30min until they completely melted and mixed. Finally, the mixed CA-LA PCMs were prepared by naturally cooling.

\subsubsection{FA/PCMs composite preparation}

In this study, fly ash (FA) was selected as a carrier material to absorb the CA-LA PCMs mixture. First, the CA-LA PCMs mixture and FA were weighted as the ratios shown in Table 3, then they were uniformly mixed and put together in a beaker. Next, put the beaker in a vacuum atmosphere with a volume of 0.9 at $40^{\circ} \mathrm{C}$ for 2 hours. Finally, after cooling at room temperature, the adsorption completed. 


\subsection{Assessment of PCMs performance}

\subsubsection{PCMs Characterization}

In this study, the micromorphological structure of raw materials and the synthetic samples was tested by a scanning electron microscope (SEM). And thermal properties, such as transition temperatures and latent heat values, were measured by a differential scanning calorimeter (DSC), with a heating rate of $10^{\circ} \mathrm{C} / \mathrm{min}$ from 5 to $45^{\circ} \mathrm{C}$ in a nitrogen atmosphere. Finally, the crystalline phases were analyzed by X-ray diffraction (XRD) by using $\mathrm{Cu} \mathrm{K} \alpha$ radiation, a scanning rate of $8 \%$ min over a scanning range of 10 90.

\subsubsection{Reference building}

In this study, a real building (in Figure 4a) would be carried out by using EnergyPlus Software to design PCMs with the appropriate transition temperature (in section 2.3.4) and to carry out an energy-saving evaluation for the proposed PCMs composite (in section 3.3). This selected real building has a total area of $3486 \mathrm{~m}^{2}$ and could be divided into two parts, the main building part, and the subsidiary building part. Among them, the main part has four layers, and the subsidiary part has two layers, with the layer height of $4 \mathrm{~m}$. The building's shape coefficient is 0.22 , the window to wall ratio is $0.132,0.130,0.140$, and 0.08 , for the south, east, north, and west wall, respectively. In addition, the heat transfer coefficient, the solar heat gain coefficient, the visible light transmittance of the outer window is $0.881 \mathrm{~W} /\left(\mathrm{m}^{2} \cdot \mathrm{K}\right), 0.411$, and 0.623 , 
respectively. Finally, in this model, its interior heat source and energy supply system would be considered as the real functional zones of the building.

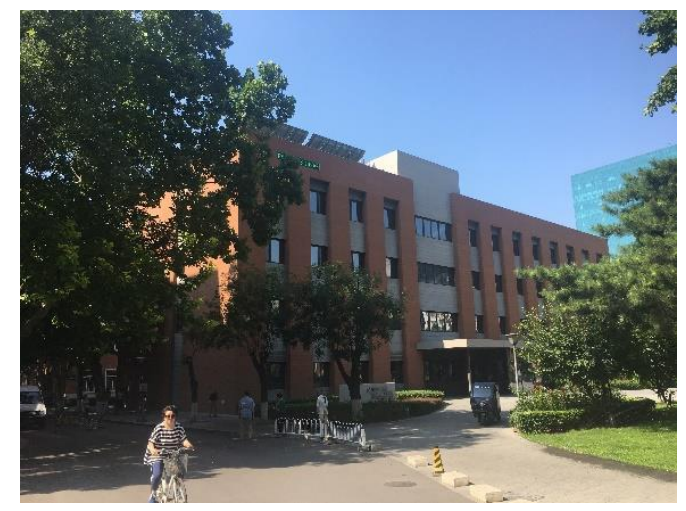

(a) The real building

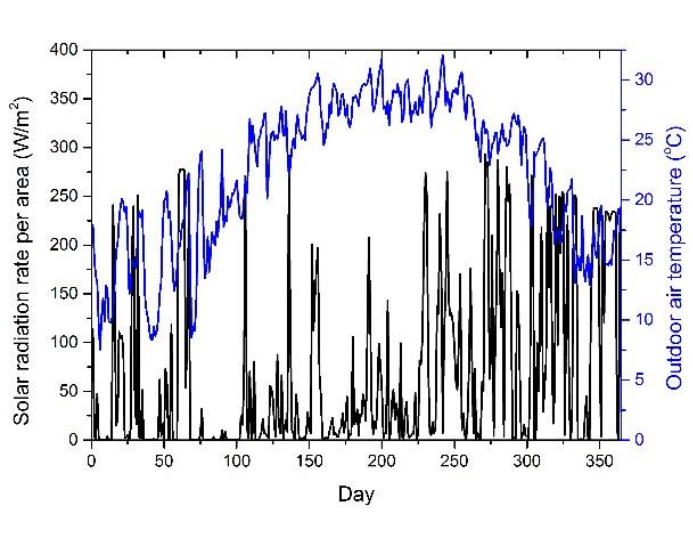

(b) Weather condition

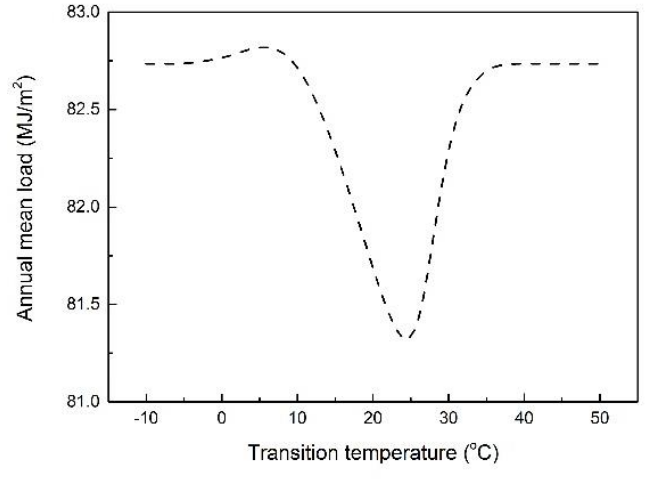

(c) Simulation results

Figure 4: Simulation by EnergyPlus in a real building

\subsubsection{Weather characterization}

According to the results in previous work [32], only for climates with small fluctuation weather conditions, PCMs with an appreciate transition temperature could have a positive contribution to energy-saving for building envelope use. Here, Guangzhou was chosen as the reference city to design PCMs and to conduct the energy simulation. As shown in Figure $4 \mathrm{~b}$, for Guangzhou the annual mean outdoor temperature and the solar radiation intensity are $22.2^{\circ} \mathrm{C}$ and $67.1 \mathrm{~W} / \mathrm{m}^{2}$, respectively. It 
can be also found that the mean outdoor temperature in Guangzhou is peaceful and has a weak fluctuation, which would benefit to the application of the PCMs.

\subsubsection{Energy simulation for designation of PCMs}

As shown in Figure $4 \mathrm{c}$, when the transition temperatures are between $10^{\circ} \mathrm{C}$ and $30^{\circ} \mathrm{C}$, PCMs can play its phase change function in Guangzhou. Only PCMs with transition temperature of about $26^{\circ} \mathrm{C}$ can get the best effect, i.e. the highest energysaving rates of $12.0 \%$, for PCMs attached to the external envelopes for a real building, which is because that this transition temperature is matched to the outdoor integrated temperature. In this study, therefore, when preparing PCMs for an envelope attaching, the appropriate transition temperature is needed to be controlled, otherwise, PCMs could not go through a phase change process, resulting in a failure of phase change effect of PCMs.

\section{Results and Discussion}

\subsection{The study of CA-LA PCMs synthesis}

To get the ideal transition temperature, CA-LA PCMs mixtures with different capric acid content were prepared accounting to the mass ratios in Table 2 and synthesized samples were tested by DSC. Figure 5 indicates the effect of the capric acid content on the transition temperature of the prepared CA-LA PCMs. It can be seen that firstly a decrease of the transition temperature occurs for PCMs with $10 \mathrm{wt} . \%$ to $80 \mathrm{wt} . \%$, then the transition temperature increases with the further addition of the capric acid. This trend is consistent with the results calculated by Schroder's equation in the design 
section. Moreover, it can further be observed that all transition temperatures are below than the own transition temperatures of the capric acid and the lauric acid, which are $32^{\circ} \mathrm{C}$ and $45^{\circ} \mathrm{C}$, respectively. Furthermore, it is interesting to note the for CA-LA PCMs with the $40 \mathrm{wt} . \%$ capric acid addition (S4), the transition temperature is $25.5^{\circ} \mathrm{C}$, which is near the design transition temperature for Guangdong PCMs application, as shown in Figure 4. The CA-LA PCMs mixture S4, therefore, was selected for further experiment.

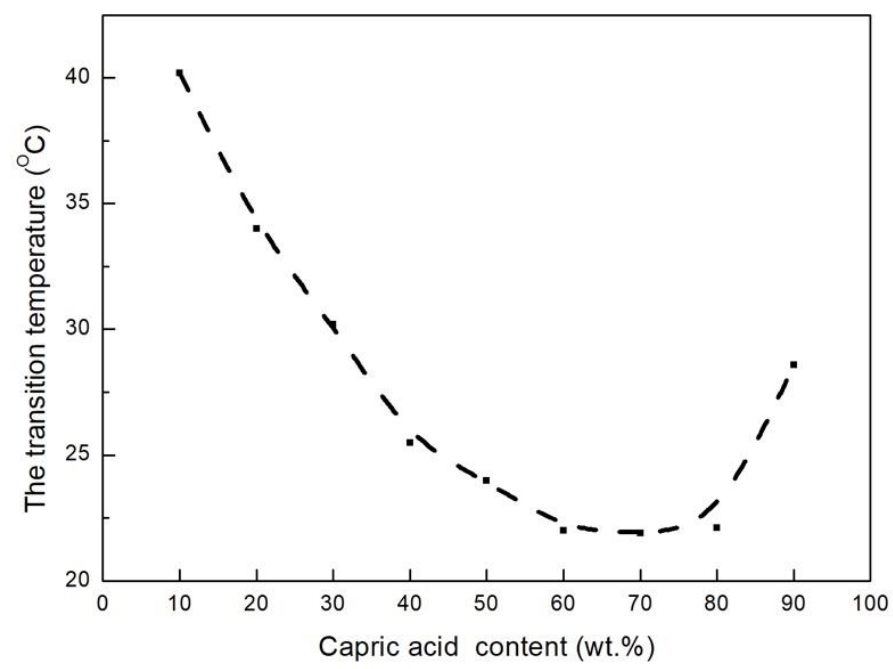

Figure 5: Transition temperatures of the PCMs mixtures with different capric acid content

Firstly, the crystal phase and thermal properties of the prepared CA-LA PCMs mixture (S4) were tested by using XRD and DSC. XRD pattern in Figure 6a shows that both of the capric acid and the lauric acid could be detected, and there is no new phase formed, indicating that the effect of mixing is good. Then in Figure $6 \mathrm{~b}$, the DSC curve indicates that for PCMs mixture S4 the latent heat value and the transition temperature 
are $140.45 \mathrm{~J} / \mathrm{g}$ and $25.5^{\circ} \mathrm{C}$, respectively, which is beneficial in its application on the building envelopes.

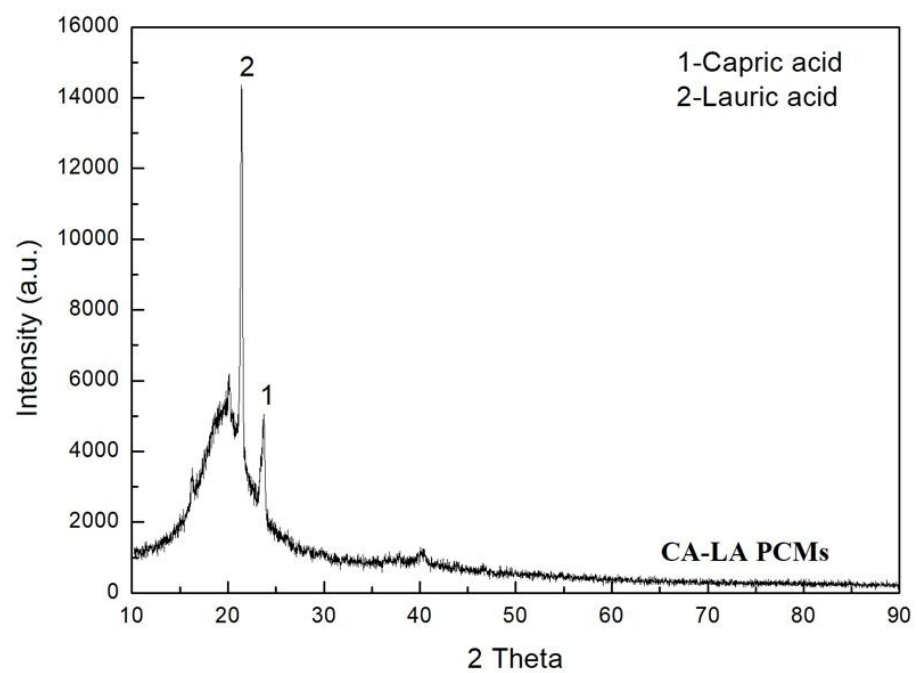

(a) XRD pattern

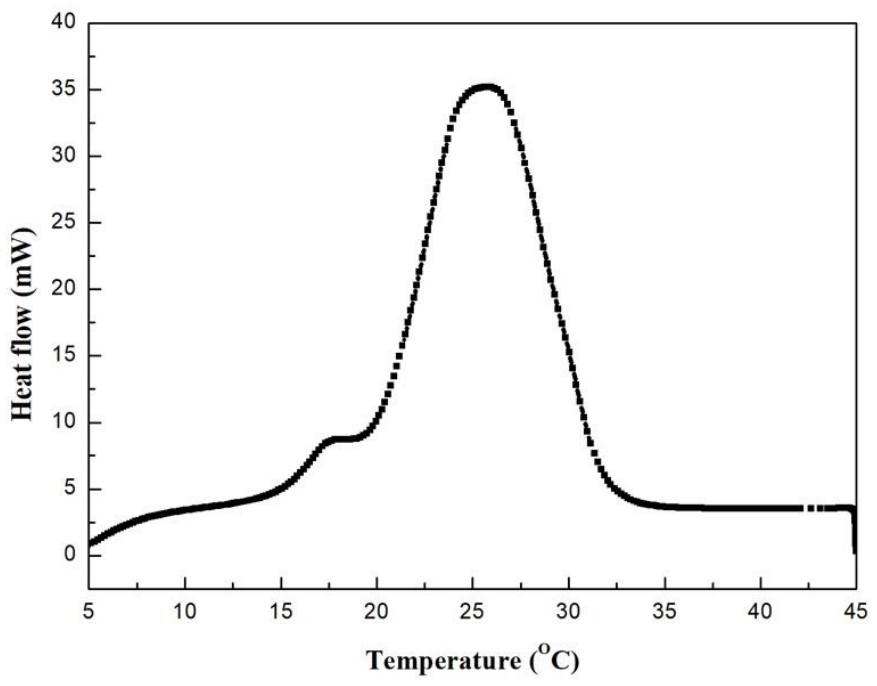

(b) DSC curve

Figure 6: XRD pattern and DSC curve of the CA-LA PCMs mixture S4 


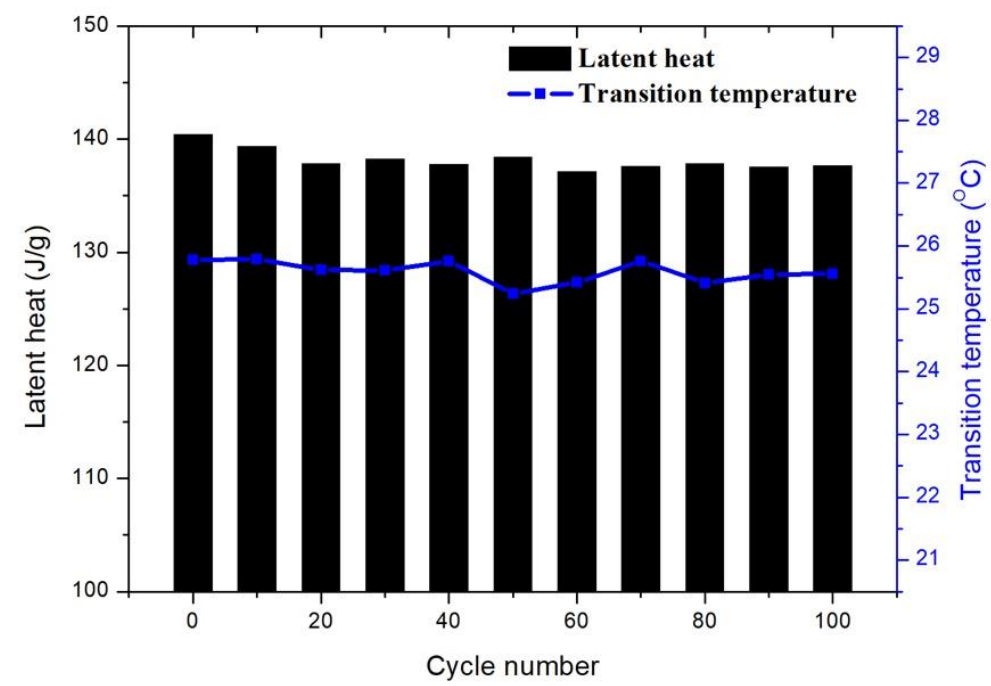

Figure 7: The results of thermal cycle experiment of the CA-LA PCMs mixture S4

Secondly, the thermal reliability was verified by a thermal cycling experiment. The cycle number of the cycling experiment was 100 times, and the CA-LA PCMs mixture S4 was repeatedly subjected to melting and solidification in heating and cooling cycle. During this process, the thermal properties (the transition temperature and the latent heat value) of the mixture S4 will be measured by DSC in every 10 times cycle. Figure 7 shows that after 100 cycles the latent heat value drops from $140.45 \mathrm{~J} / \mathrm{g}$ to $137.63 \mathrm{~J} / \mathrm{g}$, by a little dropping rate of $2 \mathrm{wt} . \%$. Moreover, Figure 7 also indicates that the transition temperature of the CA-LA PCMs mixture S4 still remains at $25.5^{\circ} \mathrm{C}$ even after 100 cycles. Both experiment results indicate that the CA-LA PCMs mixture S4 with 40wt.\% capric acid exists excellent thermal reliability, which is further beneficial in its longtime application in building envelopes. 


\subsection{The study of FA/ PCMs composite}

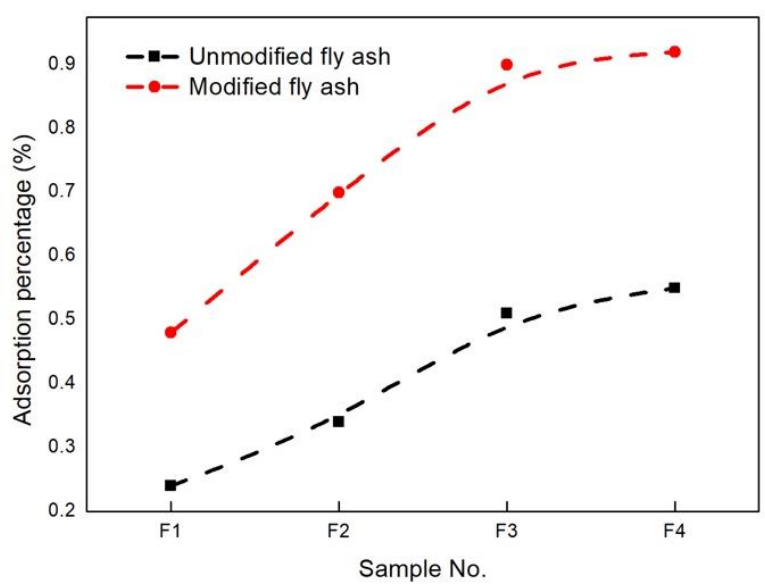

Figure 8: The adsorption percentage for composites with different fly ash content

Figure 8 shows the adsorption percentage for the FA/PCMs composites with different fly ash content. Here, in order to determine the specific adsorption percentage, the prepared composite was heated and then washed with ethanol to remove the unabsorbed PCMs from the FA surface. In Figure 8, the measured curves show that for both FA with and without heat treating modification, the adsorption percentage will increase with the FA content increase. Moreover, for modified FA, when the mass of the added fly ash exceeds 2 times that of the CA-LA PCMs, the CA-LA PCMs can be substantially completely adsorbed and the corresponding adsorption percentage of the composite F3 and F4 is high up to $90 \%$ and $92 \%$. In addition, it can be seen from this figure, for unmodified fly, the curve trend is similar as the trend for modified fly ash, i.e. the adsorption amount reaches the maximum (55\%) after the ratio of fly ash to PCMs is more than 2.5. However, it can be also clearly seen that compared with the composite with unmodified fly ash, for the high-temperature modified fly ash its 
adsorption effect could be greatly improved, and the corresponding adsorption rate increased by $76 \%$ for the composite $\mathrm{F} 3$.

Figure 9a gives the top views of the adsorption test for FA/PCMs composites under different modified fly ash ratios. First, from Figure 9a, for F1 and F2, it can be seen that there are obviously white crystals on the surface of mixture composite samples in beakers, which are formed due to the crystallization of the unabsorbed PCMs. Secondly, in F3 there is basically free of white crystals, indicating that when the modified fly ash and PCMs ratio is 2:1, the adsorption effect is the best. Thirdly, in F4, a large number of small particles appear in the beaker, this is because that the PCMs content is too small, resulting in the agglomeration of fly ash.

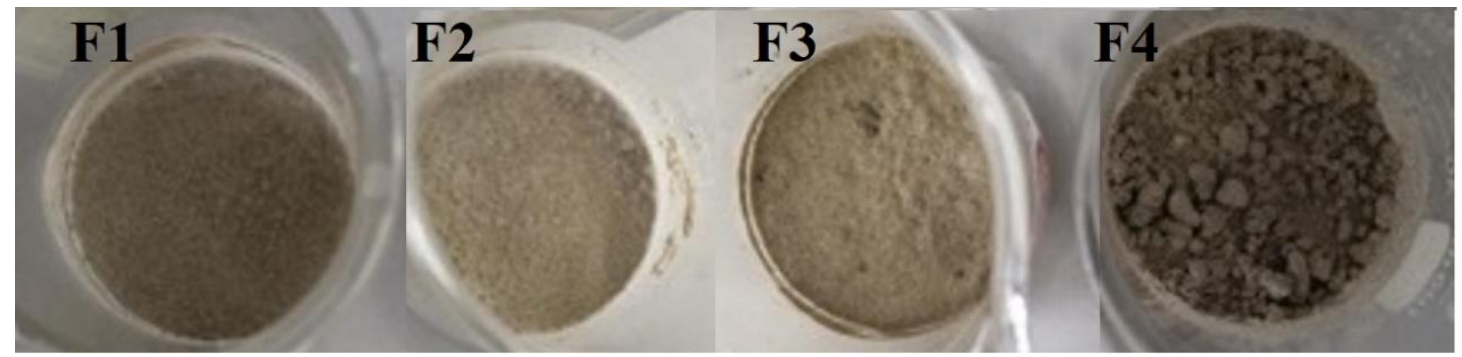

(a) Top views 

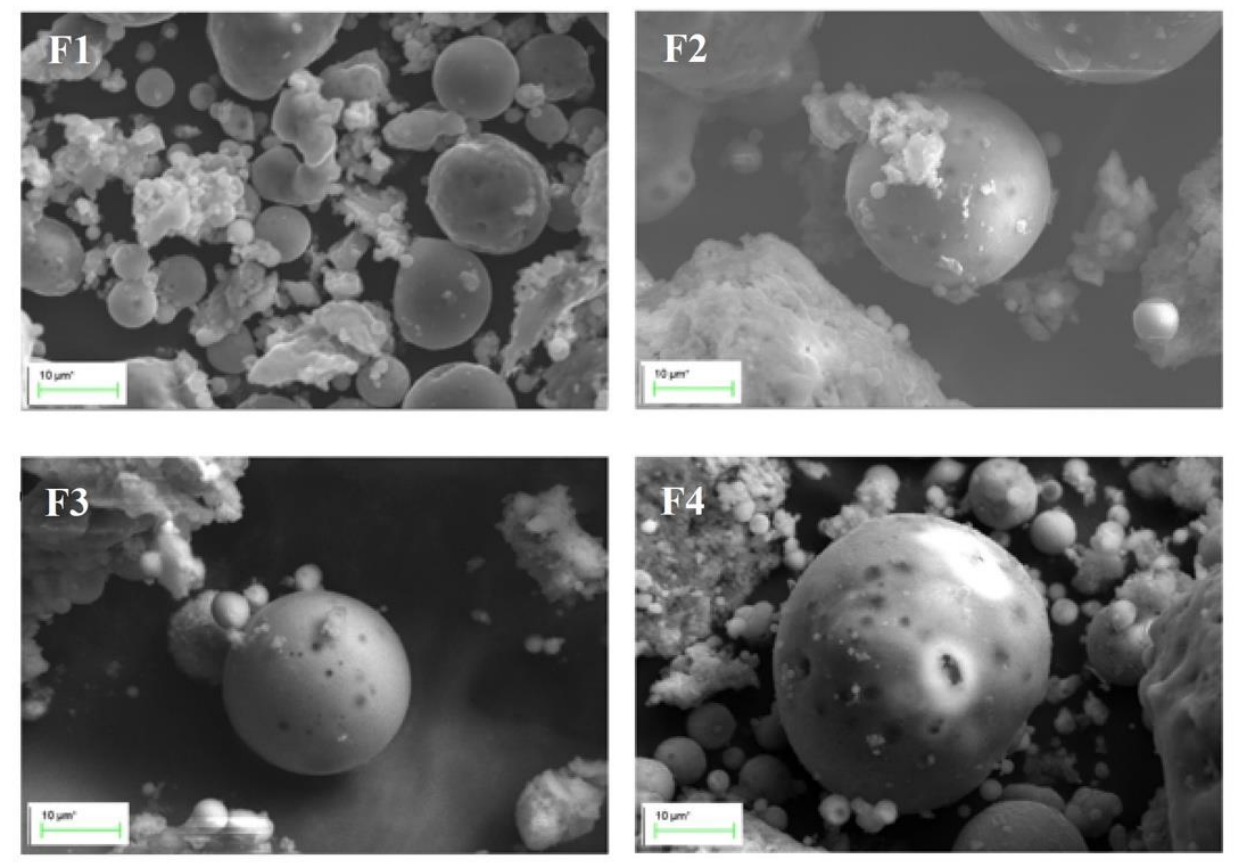

(b) SEM images

Figure 9: The Top view and SEM images of the adsorption test under different modified fly ash ratios

To further explain this phenomenon, SEM images were given in Figure 9b. For the composite F1, it can be seen that a large number of PCMs are not adsorbed. While in the composite F2, the surface of the modified fly ash is very round and smooth, which indicates that the pores of fly ash particle have been filled by PCMs, but there is still a certain amount of PCMs not being absorbed. For the SEM image of the composite F3, the surface of the modified fly ash is very smooth, indicating the pores are fully filled by PCMs, and only a very small amount of PCMs adheres to the FA surface the composite F3. Finally, for the composite F4, it can be clearly seen that the pores on the surface of the fly ash have not been completely filled. Consequently, the ratio for PCMs to FA of $1: 2$ is appropriate for synthesizing the FA/PCMs composite, i.e. the sample F3. 


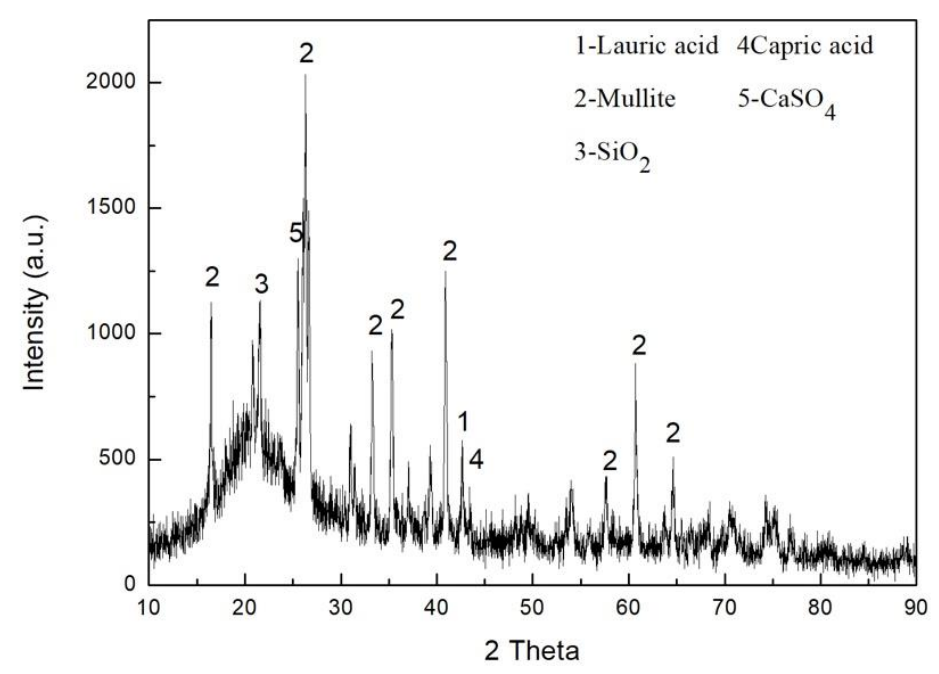

Figure 10: XRD patterns of the FA/PCMs composite F3

To further confirm the composition of the adsorbed material, the crystalline phases of the FA/PCMs composite F3 were also tested by XRD, and the test results are summarized in Figure 10. The XRD patterns indicate that the diffraction pattern of the FA/PCMs composite F3 contains all phases in CA-LA PCMs and the modified fly ash, showed in Figure 4 and Figure 6a, respectively. Moreover, no new phase is formed, indicating that there is no chemistry of the two raw materials occurred, i.e. only a physical combination of the CA-LA PCMs and the modified fly ash. In addition, compared with the pattern intensity in the pure CA-LA PCMs in Figure 6a, some decreases of the lauric acid and the capric acid were detected. This is due to the decrease in the content of both the capric acid and the lauric acid, resulting in a decrease in peak intensity.

Therefore, combined with the above SEM and XRD results, it is verified that the FA/PCMs composite could be successfully prepared, by adsorbing CA-LA PCMs into 
the modified fly ash. It is interesting to note that no chemistry of the two raw materials has occurred, and there is only a physical combination.

Finally, the thermal reliability and thermal properties of the FA/PCMs composite F3 were got by a thermal cycling experiment and DSC analysis, and the experiment results are presented in Figure 11. Here, the condition of this thermal cycling experiment is the same as that in the part of the CA-LA PCMs synthesis characterization. Figure 11a shows that after 100 cycles the latent heat value drops from $45.38 \mathrm{~J} / \mathrm{g}$ to $44.7 \mathrm{~J} / \mathrm{g}$, by a little dropping rate of $1.5 \mathrm{wt}$.\%. Moreover, Figure $11 \mathrm{~b}$ also indicates that the transition temperature of the FA/PCMs composite F3 still remains at $25.5^{\circ} \mathrm{C}$ even after 100 cycles. It can be concluded that the FA/PCMs composite F3 has excellent properties, which is feasible for use in building envelopes.

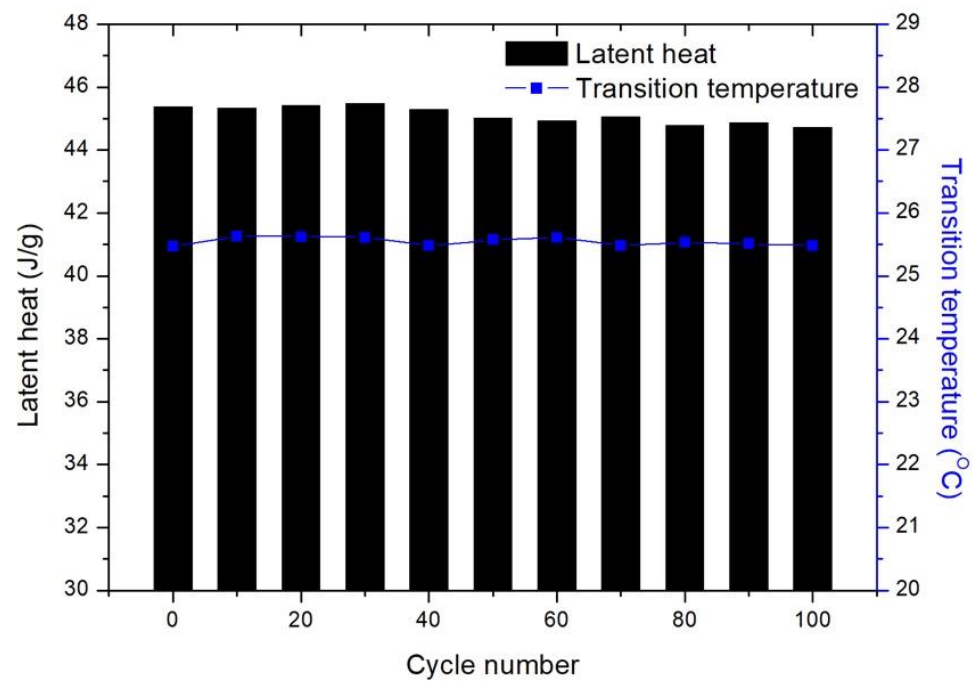

(a) Thermal cycle experiments 


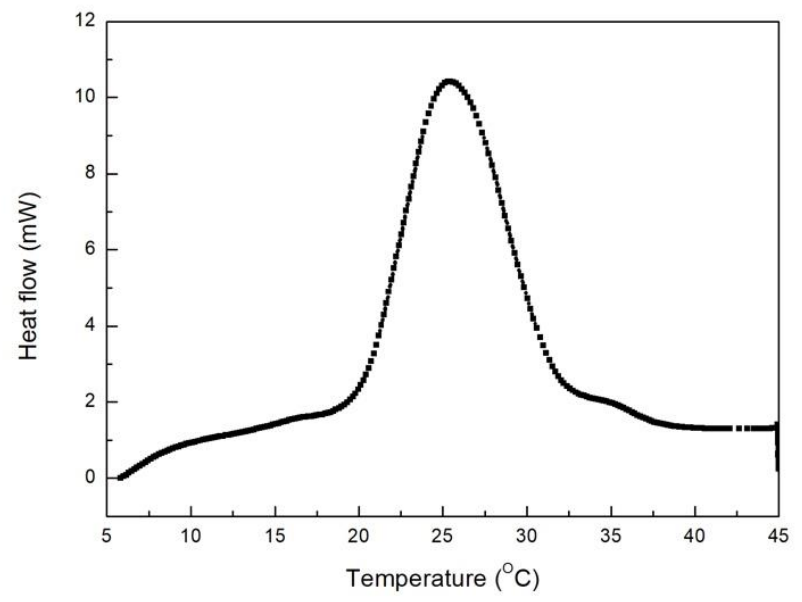

(b) DSC curves

Figure 11: DSC curves of the PCMs and the FA/ PCMs composite

\subsection{Building energy-saving evaluation}

In this part, two kinds of building envelopes would be used as basement groups in the simulation, and they are $200 \mathrm{~mm}$ heavy concrete and $200 \mathrm{~mm}$ common concrete with the corresponding thermal conductivities of 1.95 and $1.11 \mathrm{~W} /(\mathrm{m} \cdot \mathrm{K})$, named as B1 and B2. To calculate the energy-saving rate, 50\% FA/PCMs composite would be added evenly in these two concrete materials, as two comparison groups named as $\mathrm{C} 1$ and $\mathrm{C} 2$.

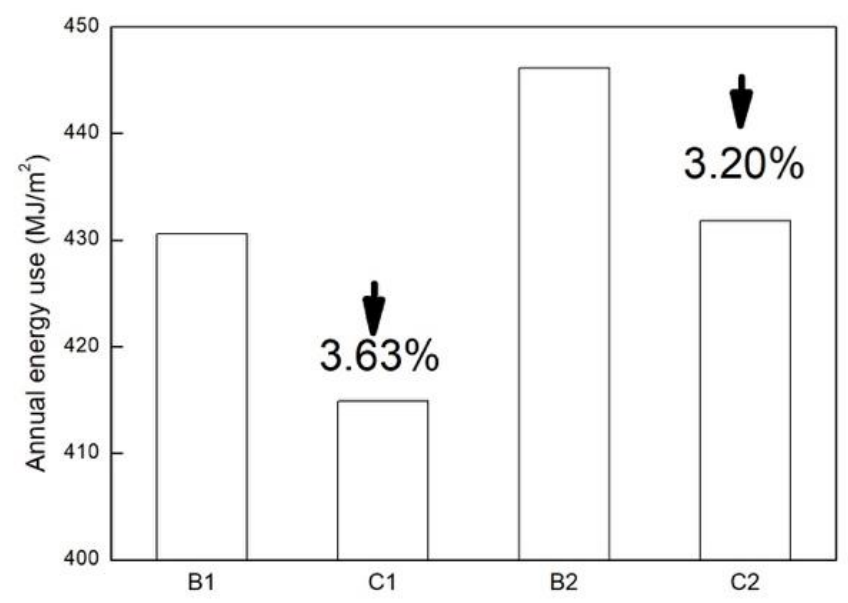

(a) Annual energy use per area 


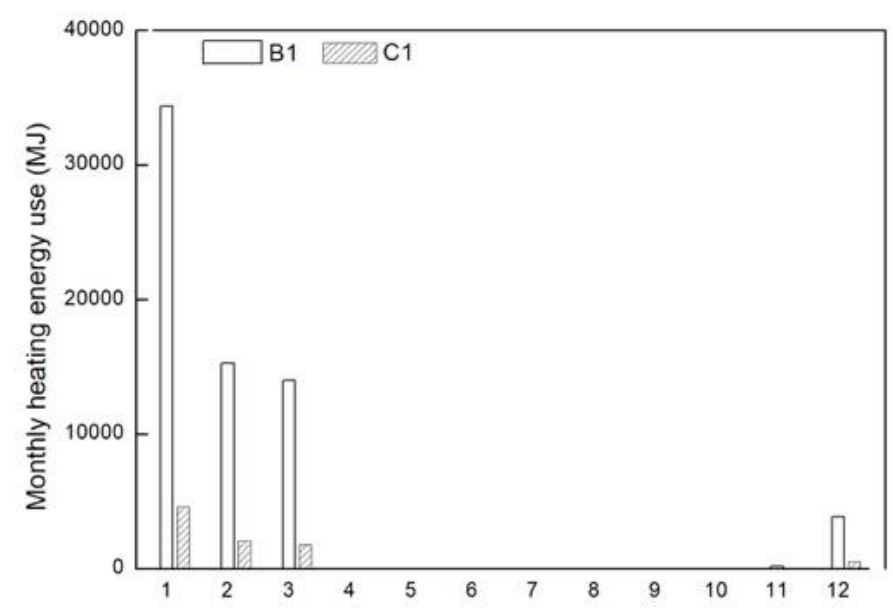

(b) Monthly heating energy use for B1 and C1

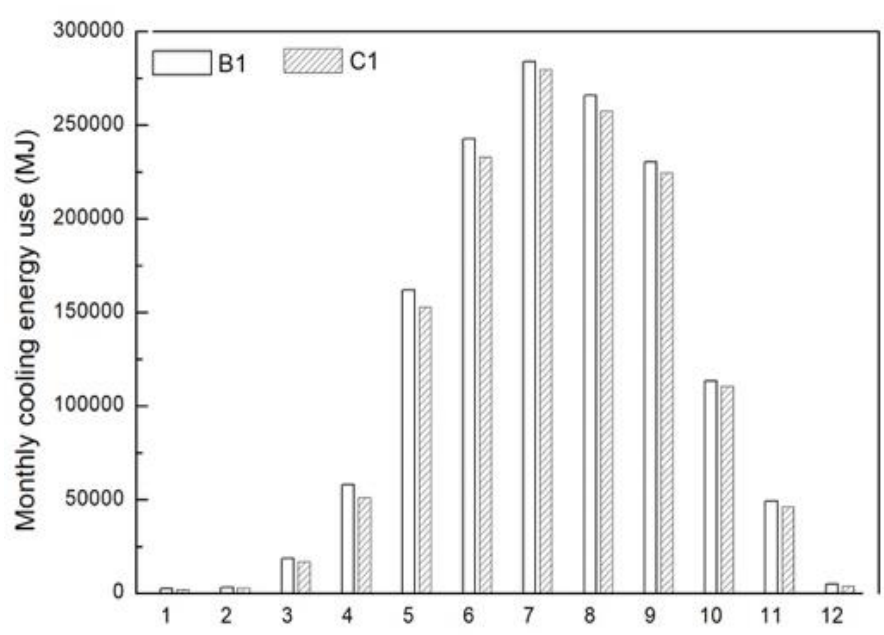

(c) Monthly cooling energy use for B1 and C1

Figure 12: Annual and monthly energy use for different envelopes

First, Figure 12a shows the annual energy use for these two groups of building envelopes. It can be seen that, for the buildings B1 and B2 with 200mm heavy concrete and $200 \mathrm{~mm}$ common concrete, the energy use is $430.6 \mathrm{MJ} / \mathrm{m}^{2}$ and $446.1 \mathrm{MJ} / \mathrm{m}^{2}$, respectively. While, for the buildings $\mathrm{C} 1$ and $\mathrm{C} 2$ with $50 \%$ the proposed FA/PCMs composite replacement, the corresponding energy use is $414.9 \mathrm{MJ} / \mathrm{m}^{2}$ and $431.8 \mathrm{MJ} / \mathrm{m}^{2}$, with the reduction rate of $3.63 \%$ and $3.20 \%$, respectively. Thus, it can be concluded that the using PCMs composite on the building envelopes could realize the reduction of the building energy use. Moreover, it can be imagined that if this proposed new 
FA/PCMs composite could be applied in the new buildings under construction, a large amount of energy could be saved. Besides, due to the FA was used to carry the PCMs mixture for the synthesis PCMs composite, the large amount of application of this composite would lead to large quantities of recycling of the solid waste FA.

Secondly, taking the buildings $\mathrm{B} 1$ and $\mathrm{C} 1$ as an example, monthly energy use of this buildings was compared in Figure $12 \mathrm{~b}$ and $\mathrm{c}$. It can be found that no matter the heating energy use or the cooling energy use, nearly in each month the reduction of energy use could be got for the building $\mathrm{C} 1$ when comparing to the energy use in the building B1. This shows that the application of the proposed FA/PCMs composite could has a positive effect in energy-saving every month, which is due to the mild climate in Guangdong and its small weather fluctuations in the whole year.

\section{Conclusions}

This study developed a new PCMs composite and evaluated its energy performance. The specific conclusion is as follow.

Firstly, a reference method is given to design the transition temperature of PCMs. For example, for Guangzhou, the PCMs transition temperature ranges from $10^{\circ} \mathrm{C}$ to $30^{\circ} \mathrm{C}$ lead to a positive effect of phase change function, and PCMs with a transition temperature of about $26^{\circ} \mathrm{C}$ can get the best effect.

Secondly, a new PCMs composite with $25.5^{\circ} \mathrm{C}$ transition temperature was synthesized by mixing capric acid and lauric acid in a mass ratio of 4:6 as PCMs mixture 
and being absorbed by fly ash. The experiment results show that the optimum FA/PCMs composite has a latent heat of $45.38 \mathrm{~J} / \mathrm{g}$ and it has good thermal reliabilities.

Thirdly, the energy simulation results by EnergyPlus show that the proposed composite could reduce the building energy use, which has a good contribution for building energy efficiency. Moreover, this application of the new composite would also provide an effective method for the reuse of solid waste fly ash.

\section{Acknowledgments}

This research was funded by National Key R\&D Plan of China (2017YFC0702600). Supports by National Natural Science Foundation of China (51708022), The Fundamental Research Funds for the Central Universities (FRF-TP-18-024A2), and the program of China Scholarships Council (201806465006) were also acknowledged.

\section{References}

[1]. Robati M , Mccarthy T J , Kokogiannakis G . Integrated life cycle cost method for sustainable structural design by focusing on a benchmark office building in Australia.[J]. Energy and Buildings, 2018:S0378778817332668.

[2]. Kyriaki E , Konstantinidou C , Giama E , et al. Life cycle analysis (LCA) and life cycle cost analysis (LCCA) of phase change materials (PCM) for thermal applications: A review[J]. International Journal of Energy Research, 2017.

[3]. CAafi K, Daouas N . A life-cycle cost analysis for an optimum combination of cool coating and thermal insulation of residential building roofs in Tunisia[J]. Energy, 2018:S0360544218306005. 
[4]. Shi J , Lin K W , Chen Z Q, et al. Annual Dynamic Thermal Performance of Solar Water Heaters:A Case Study in China's Jiangsu Province[J]. Energy and Buildings, 2018, 173.

[5]. Wu Y, Krishnan P, Yu L E , et al. Using lightweight cement composite and photocatalytic coating to reduce cooling energy consumption of buildings[J]. Construction and Building Materials, 2017, 145:555-564.

[6]. CArtori I, CAndberg N H , Bratteb? H . Dynamic building stock modelling: General algorithm and exemplification for Norway[J]. Energy and Buildings, 2016:S037877881630487X

[7]. Konstantinidou C A, Lang W, Papadopoulos A M. Multiobjective optimization of a building envelope with the use of phase change materials (PCMs) in Mediterranean climates[J]. International Journal of Energy Research, 2018(4).

[8]. Chou S K, Chang W L. A generalized methodology for determining the total heat gain through building envelopes[J]. International Journal of Energy Research, 2015, 20(10):887-901.

[9]. Ji R, Wu S, Yan C, et al. Preparation and characterization of the one-piece wall ceramic board by using solid wastes[J]. Ceramics International, 2017:S0272884217304625.

[10]. Zhou B, Yoshioka H, Noguchi T, et al. Numerical prediction of mass loss rate of expanded polystyrene (EPS) used for external thermal insulation composite systems (ETICS) in cone calorimeter[J]. Fire \& Materials, 2017(8).

[11]. Ricciu R , BeCAlduch L A, Galatioto A, et al. Thermal characterization of 
insulating materials $[\mathrm{J}]$. Renewable and Sustainable Energy Reviews, 2017:S1364032117310018.

[12]. Zhu M , Ji R, Li Z , et al. Preparation of glass ceramic foams for thermal insulation applications from coal fly ash and waste glass $[\mathrm{J}]$. Construction and Building Materials, 2016, 112:398-405.

[13]. Ling H, Chen C, Guan Y, et al. Active heat storage characteristics of activepassive triple wall with phase change material[J]. Solar Energy, 2014, 110:276-285.

[14]. Auzeby M, Shen W, Underwood C, et al. Using Phase Change Materials to Reduce Overheating Issues in UK Residential Buildings $\hat{\xi}[\mathrm{J}]$. Energy Procedia, 2017, $105: 4072-4077$.

[15]. Ji R, Zhang Z, He Y, et al. Simulating the effects of anchors on the thermal performance of building insulation systems [J]. Energy and Buildings, 2017, 140:501507.

[16]. Rashidi, S., Esfahani, J. A., \& Karimi, N. Porous materials in building energy technologies-A review of the applications, modelling and experiments $[\mathrm{J}]$. Renewable and Sustainable Energy Reviews, 2018, 91: 229-247.

[17]. Zhou, Y., Chuck, W. F., \& Zhang, G. Study on heat-transfer mechanism of wallboards containing active phase change material and parameter optimization with ventilation [J]. Applied Thermal Engineering, 2018, 144: 1091-1108.

[18]. Ahmet CArı, Bicer A, Karaipekli A, et al. Preparation, characterization and thermal regulation performance of cement based-composite phase change material[J]. Solar Energy Materials \& Solar Cells, 2018, 174:523-529. 
[19]. Mankel, C., Caggiano, A., Ukrainczyk, N., \& Koenders, E. Thermal energy storage characterization of cement-based systems containing Microencapsulated-PCMs [J]. Construction and Building Materials, 2019, 199: 307-320.

[20]. Liu L, Lu G, Qiu G, et al. Characterization of novel shape - stabilized phase change material mortar: Portland cement containing Na2SO4 $\cdot 10 \mathrm{H} 2 \mathrm{O}$ and fly ash for energy - efficient building[J]. International Journal of Energy Research, 2019.

[21]. CHENG, WenLong, WU, et al. A new kind of shape-stabilized PCMs with positive temperature coefficient (PTC) effect[J]. Energy Conversion \& Management, 2014, 79(3):470-476.

[22]. Y. Özonur, Mazman M, H. Ö. Paksoy, et al. Microencapsulation of coco fatty acid mixture for thermal energy storage with phase change material[J]. International Journal of Energy Research, 2006, 30(10):741-749.

[23]. Mitran R A, Berger D, Matei C. Improving thermal properties of shapestabilized phase change materials containing lauric acid and mesocellular foam silica by assessing thermodynamic properties of the non-melting layer $[\mathrm{J}]$. Thermochimica Acta, 2018, 660:70-76.

[24]. Ru J, Zhang Z, Chen Y, et al. Preparation of novel ceramic tiles with high Al 2 O 3 content derived from coal fly ash[J]. Construction \& Building Materials, 2016, 114:888-895.

[25]. Wang S, Luo K. Atmospheric emission of mercury due to combustion of steam coal and domestic coal in China[J]. Atmospheric Environment, 2017, 162:45-54.

[26]. 2Zhu T Y, Kuang J Y, Xu W Q, et al. Study on Mercury Adsorption Performance 
of Modified Fly Ash[J]. Advanced Materials Research, 2011, 343-344:246-249.

[27]. Q. Lü, X. Dong, Z. Zhu, et al., Environment-oriented low-cost porous mullite ceramic membrane supports fabricated from coal gangue and bauxite, J.Hazard. Mater. 273 (6) (2014) 136-145.

[28]. Pei S L, Pan S Y, Li Y M, et al. Environmental Benefit Assessment for the Carbonation Process of Petroleum Coke Fly Ash in a Rotating Packed Bed[J]. Environmental Science \& Technology, 2017, 51(18):acs.est.7b00708.

[29]. Hlekelele L, Franklyn P J, Dziike F, et al. Novel synthesis of Ag decorated TiO2 anchored on zeolites derived from coal fly ash for the photodegradation of bisphenolA[J]. New Journal of Chemistry, 2017, 42(3):10.1039.C7NJ02885G.

[30]. Bada S O, Potgieter-Vermaak S. Evaluation and treatment of coal fly ash for adsorption application[J]. Leonardo Electronic Journal of Practices and Technologies, 2008, 12: 37-48.

[31]. Shilei L, Neng Z, Guohui F. Eutectic mixtures of capric acid and lauric acid applied in building wallboards for heat energy storage[J]. Energy and Buildings, 2006, 38(6): 708-711.

[32]. Ji R, Zou Z, Chen M, et al. Numerical assessing energy performance for building envelopes with phase change material[J]. International Journal of Energy Research, 2018. 
Table 1: The chemical composition of fly ash

\begin{tabular}{lllllllll}
\hline Component & $\mathrm{SiO}_{2}$ & $\mathrm{Al}_{2} \mathrm{O}_{3}$ & $\mathrm{Fe}_{2} \mathrm{O}_{3}$ & $\mathrm{CaO}$ & $\mathrm{TiO}_{2}$ & $\mathrm{MgO}$ & $\mathrm{SO}_{3}$ & Others \\
\hline $\begin{array}{l}\text { Content } \\
\text { (wt.\%) }\end{array}$ & 45.80 & 39.18 & 2.91 & 2.84 & 1.19 & 0.81 & 0.42 & 6.85 \\
\hline
\end{tabular}

Table 2: Main raw materials compositions (wt.\%) of the CA-LA PCMs

\begin{tabular}{cccccccccc}
\hline Sample No. & S1 & S2 & S3 & S4 & S5 & S6 & S7 & S8 & S9 \\
\hline CA content $/$ wt.\% & 10 & 20 & 30 & 40 & 50 & 60 & 70 & 80 & 90 \\
$\begin{array}{c}\text { Theoretical transition } \\
\text { temperature } /{ }^{\circ} \mathrm{C}\end{array}$ & 36.2 & 29.8 & 24.9 & 21 & 16.2 & 18.7 & 21.4 & 24.5 & 28
\end{tabular}

Table 3: Main raw materials ratios of FA/ PCMs composite

\begin{tabular}{ccccc}
\hline Sample No. & F1 & F2 & F3 & F4 \\
\hline Fly ash/PCMs & $1: 1$ & $1.5: 1$ & $2: 1$ & $2.5: 1$ \\
\hline
\end{tabular}




\section{Table and Figure captions:}

Table 1: The chemical composition of fly ash

Table 2: Main raw materials compositions (wt.\%) of the CA-LA PCMs.

Table 3: Main raw materials ratios of FA/ PCMs composite

Figure 1: DSC curves of the capric acid and lauric acid

Figure 2: SEM images of the fly ash (a) before and (b) after modification

Figure 3: XRD patterns of the fly ash before after and after modification

Figure 4: Simulation by EnergyPlus in a real building

Figure 5: Transition temperatures of the PCMs mixtures with different capric acid content

Figure 6: XRD pattern and DSC curve of the CA-LA PCMs mixture S4

Figure 6: The results of thermal cycle experiment of the CA-LA PCMs mixture S4

Figure 8: The adsorption percentage for composites with different fly ash content

Figure 9: The SEM images of adsorption test under different modified fly ash ratios

Figure 10: XRD patterns of the FA/PCMs composite F3

Figure 11: DSC curves of the FA/PCMs composite F3

Figure 12: Annual and monthly energy use for different envelopes 